\title{
Association of Surrogate Objective Measures With Work Relative Value Units
}

\author{
Tam Ramsey, MD, Tyler Ostrowski, BS, Kent Curran, MBA, Jason Mouzakes, MD, Neil Gildener-Leapman, MD \\ Department of Otolaryngology-Head and Neck Surgery, Albany Medical Center, Albany, NY
}

Background: The determination of accurate measures of evaluating surgeon work for reimbursement is poorly characterized. This study defines the correlation of surgical work relative value units (work RVUs) with several surrogate objective measures for otolaryngologic work. The defined surrogate objective measures evaluated in this study are length of hospital stay (LOS), operative time, 30-day mortality, 30-day unplanned readmission, 30-day reoperation, and 30-day morbidity.

Methods: We collected data on otolaryngologic cases from 2016 to 2018 from the American College of Surgeons National Surgical Quality Improvement Program. Pearson correlation coefficient was used to associate work RVUs with objective measures of surgeon work. Linear regressions were used to identify predictors of work RVUs from the surrogate objective measures. Studentized residuals were used to identify outlying procedures.

Results: Work RVUs correlated strongly with operative time ( $R=0.6775), 30$-day readmission $(R=0.6100)$, and LOS ( $R=0.6083)$; moderately with 30-day reoperation $(R=0.5257)$ and 30-day morbidity $(R=0.4842)$; and very weakly with 30-day mortality $(R=0.1383)$. The best predictors for work RVUs based on multivariable linear regression analysis were morbidity, reoperation, and operative time. Analysis revealed that the projected work RVU is 12.23 units higher than the current value for excision of bone, mandible (Current Procedural Terminology [CPT] code 21025) and 19.48 units lower than the current value for resection/excision of lesion infratemporal fossa space apex extradural (CPT code 61605).

Conclusion: Using objective surrogate measures for time and intensity of physician work in head and neck cases may improve work RVU assignment accuracy compared to the current system of physician survey. Future investigation with additional objective parameters may be beneficial to make work RVU assignments less subjective.

Keywords: Compensation, head and neck, morbidity, operative time, otolaryngology, reimbursement, relative value unit, reoperation

Address correspondence to Neil Gildener-Leapman, MD, Department of Otolaryngology-Head and Neck Surgery, Albany Medical Center, 50 New Scotland Ave., Albany, NY 12208. Tel: (518) 262-5831. Email: gildenn2@amc.edu

\section{INTRODUCTION}

Concerns about the rising costs of Medicare expenditures and low reimbursement rates for primary care physicians became prevalent in late $1980 .^{1}$ This conversation prompted researchers to create the resource-based relative value scale (RBRVS) for physician reimbursement. ${ }^{1}$ The RBRVS was based on the conditions of a physician's time or work associated with a service, the cost of running a practice, and the opportunity cost of physician training payback during the course of their career. ${ }^{1}$ The predecessor of the Centers for Medicare and Medicaid Services (CMS), the Health Care Financing Administration, first implemented relative value units (RVUs) as a standard unit to measure physician work in 1992 to define reimbursement rates, a move that was supported by researchers in the years prior. ${ }^{1-3}$ With this implementation, the American Medical Association (AMA), which controls the Current Procedural Terminology (CPT) codes that are linked to the RBRVS, established the Relative Value Scale Update Committee (RUC) to provide a reliable bridge between practicing physicians and CMS. ${ }^{1,4}$ The RUC consists of professional members of the AMA and representatives from national societies of various medical specialties. The RUC generally meets thrice yearly to provide recommendations to CMS about the relative value of work so CMS can annually reevaluate its Medicare RBRVS and Physician Fee Schedule. ${ }^{4}$

Work RVU, a measure of surgeon work, has 3 building blocks: (1) preservice (eg, reviewing records, case discussion, and preparing for surgery); (2) intraservice (eg, intraoperative period from first incision to closing the incision); and (3) postservice (eg, global surgical period including recovery room time and inpatient hospital stay). ${ }^{5}$ Notably, work RVU calculation for primary care providers may include different variables. For surgeons and physicians, however, the time and intensity associated with their respective building blocks are reflected in the final work RVU assignment for a service. The RUC obtains these estimations from physician surveys conducted by specialty societies. To account 
for potential bias or overestimations of operative time from survey responses, the RUC generally uses the operative time that falls in the 25th percentile of survey responses. Requests for reevaluation are a tool that specialty societies may use to adjust the RVU of a specific procedure. In instances of reevaluation requests, societies often feel work RVUs are undervalued because of factors such as advances in technology and updates in patient risk profiles. On the other hand, the RUC reserves the right to deny reevaluation requests. ${ }^{4,6}$

Currently, no database exists that can accurately measure time and intensity for all 3 building blocks so that work RVU assignments can be verified. However, we believe that surrogate objective measures for surgeon work (ie, the 3 building blocks) should be evaluated to provide evidence for updating work RVUs and claiming appropriate surgical compensation. In fact, studies in different surgical specialties found that length of hospital stay (LOS), morbidity, mortality, reoperation, unplanned readmissions, and operative time correlate with work RVUs and should be used in work RVU reevaluation. , $^{5,7}$ Therefore, the objective of this study was to define the correlation of work RVUs with surgeon work in otolaryngology using the aforementioned measures. The database used, the American College of Surgeons National Surgical Quality Improvement Program (NSQIP), only includes major inpatient and outpatient otolaryngology cases; thus, the procedures evaluated in this study are limited to such.

\section{METHODS}

We combined the NSQIP data from 2016 to 2018 for analysis in this study. The operative time for each CPT code in concurrent cases is inseparable and likely results in multiple RVUs being billed for cases with multiple surgeons. Therefore, we excluded any encounter involving more than one surgeon and/or having concurrent CPT codes. We only analyzed cases performed by otolaryngologists. We also eliminated any CPT code that had fewer than 25 associated encounters.

From the CPT codes selected, we collected data on the following variables: LOS, operative time, 30-day mortality, 30-day unplanned readmission, 30-day reoperation, and 30day morbidity. Morbidity is defined as any serious adverse events that occurred within 30 days of the procedure, including surgical site infection, wound disruption, pneumonia, unplanned intubation, pulmonary embolism, acute renal failure, cardiovascular accident or stroke, cardiac arrest, myocardial infarction, bleeding that required transfusion, and septic shock.

Median values were used for analyses of LOS and operative time. Means of percentages were used for analyses in 30-day mortality, 30-day unplanned readmission, 30-day reoperation, and 30-day morbidity.

SAS software, version 9.4 (SAS Institute Inc) was used to perform statistical analyses. Bivariate and multivariable linear regressions were used to identify predictors of work RVUs from the above variables. In addition, correlations between each variable and work RVUs were calculated using Pearson correlation coefficient. We defined absolute $R$ values as follows: very strong if $R$ is between 0.8 and 1.0, strong if $R$ is between 0.6 and 0.79 , moderate if $R$ is between 0.4 and 0.59 , weak if $R$ is between 0.2 and 0.39 , and very weak if $R$ is $<0.19$. $P$ values $<0.10$ were considered significant.

Studentized residuals, a statistical method to detect outliers based on the mean square error with the investigated target excluded, were used to identify outlying work RVUs in the bivariable and multivariable linear regressions. Work RVUs with studentized residuals $<-2$ or $>2$ were considered outliers. Based on bivariate and multivariable linear regression analyses, projected work RVUs were calculated. The difference between projected work RVU and actual work RVU was determined.

This study was designated exempt by the institutional review board at Albany Medical Center.

\section{RESULTS}

We identified 110,795 otolaryngologic cases in the years 2016, 2017, and 2018. We excluded 1,201 cases with concurrent CPT codes, 26,150 cases with a secondary procedure, and 2,488 cases with both concurrent CPT codes and a secondary procedure. From the remaining 80,956 cases, only 41,666 cases were otolaryngologic, with 53 CPT codes represented. Only 43 CPT codes had more than 25 patient encounters, for a total of 41,554 cases included in our final analysis. All 43 CPT codes were defined for head and neck surgeries.

The mean work RVU for the procedures analyzed was $16.32 \pm 9.49$, ranging from 1.56 for excision of tongue without closure (CPT code 41110) to 38.81 for total laryngectomy with radical neck dissection (CPT code 31365 ). Table 1 shows the 43 CPT codes with their associated work RVUs and procedural frequencies.

The mean of the median operative times of 43 CPT codes was 133.55 minutes \pm 111.29 minutes. The mean of the median LOS was 1.67 days \pm 2.43 days. The means of morbidity percentage, readmission percentage, reoperation percentage, and mortality percentage were $6.58 \% \pm 9.34 \%$, $3.62 \% \pm 3.46 \%, 3.52 \% \pm 5.35 \%$, and $0.26 \% \pm 0.56 \%$, respectively. Strong correlations were observed between work RVU and operative time $(R=0.6775)$, 30-day readmission $(R=0.6100)$, and LOS $(R=0.6083)$. Moderate correlations were observed between work RVU and 30-day reoperation $(R=0.5257)$ and 30 -day morbidity $(R=0.4842)$. However, a very weak correlation was observed between work RVU and 30-day mortality $(R=0.1383)$. Bivariable linear regression demonstrated that the variables operative time, LOS, reoperation and readmission within 30 days, and 30 day morbidity were predictors of work RVU. Mortality within 30 days was not predictive of work RVU (Figure).

Every minute increase in operative time yields a work RVU increase of 0.0577 units $(95 \% \mathrm{Cl} 0.0380$ to 0.0775 ; $P<0.001)$. A 1-day increase in LOS leads to an increase of 2.368 units in work RVU $(95 \% \mathrm{Cl} 1.393$ to $3.342 ; P<0.001)$. Similarly, a $1 \%$ increase in morbidity, readmission, and reoperation leads to an increase of 0.4917 units $(95 \% \mathrm{Cl} 0.2115$ to $0.7720 ; P<0.001), 1.673$ units $(95 \% \mathrm{Cl} 0.9877$ to 2.3589 ; $P<0.001)$, and 0.9321 units $(95 \% \mathrm{Cl} 0.4564$ to 1.4079 ; $P<0.001)$ in work RVU, respectively. No linear correlation was observed between mortality and work RVU $(95 \% \mathrm{Cl}$ -2.9493 to $7.6331 ; P=0.377$ ) (Figure).

The predictors for work RVU based on multivariable linear regression analysis of the other 5 variables were morbidity $(P<0.005)$, operative time $(P<0.001)$, and reoperation 
Table 1. Case Mix, Frequency, Work Relative Value Unit (RVU), Operative Time, Length of Stay (LOS), Morbidity, Readmission, Reoperation, and Mortality for 43 Representative Otolaryngology Procedures

\begin{tabular}{|c|c|c|c|c|c|c|c|c|c|}
\hline $\begin{array}{l}\text { CPT } \\
\text { Code }\end{array}$ & Procedure & Frequency & $\begin{array}{l}\text { Mean Work } \\
\text { RVU }\end{array}$ & $\begin{array}{c}\text { Median } \\
\text { Operative } \\
\text { Time, min }\end{array}$ & $\begin{array}{l}\text { Median } \\
\text { LOS, days }\end{array}$ & $\begin{array}{c}\text { Mean } \\
\text { Morbidity, } \\
\%\end{array}$ & $\begin{array}{c}\text { Mean Read- } \\
\text { mission, } \\
\%\end{array}$ & $\begin{array}{c}\text { Mean Reop- } \\
\text { eration, } \\
\%\end{array}$ & $\begin{array}{c}\text { Mean } \\
\text { Mortality, } \\
\%\end{array}$ \\
\hline 31365 & Laryngectomy total with radical neck dissection & 39 & 38.81 & 402 & 9 & 15.38 & 12.82 & 7.69 & 0 \\
\hline 15756 & $\begin{array}{l}\text { Free muscle/myocutaneous flap with microvascular } \\
\text { anastomosis }\end{array}$ & 29 & 36.94 & 502 & 8 & 34.48 & 13.79 & 20.69 & 0 \\
\hline 61605 & $\begin{array}{l}\text { Resection or excision of neoplastic, vascular, or infectious } \\
\text { lesion of infratemporal fossa, petrous apex; extradural }\end{array}$ & 31 & 32.57 & 102 & 1 & 6.45 & 3.23 & 3.23 & 0 \\
\hline 41135 & Partial glossectomy with unilateral radical neck dissection & 95 & 30.14 & 180 & 3 & 11.58 & 6.32 & 5.26 & 1.05 \\
\hline 31360 & Total laryngectomy without neck dissection & 88 & 29.91 & 370 & 8 & 27.27 & 12.5 & 10.23 & 1.14 \\
\hline 41150 & $\begin{array}{l}\text { Composite glossectomy with floor and mandibular } \\
\text { resection }\end{array}$ & 25 & 29.86 & 264 & 6 & 32 & 12 & 28 & 0 \\
\hline 60254 & Total/subtotal thyroidectomy with radical neck dissection & 250 & 28.42 & 208 & 2 & 4 & 2 & 3.2 & 0.4 \\
\hline 38724 & Cervical lymphadenectomy with modified neck dissection & 1,197 & 23.95 & 150 & 1 & 4.68 & 4.01 & 3.43 & 0.08 \\
\hline 60270 & Thyroidectomy with substernal split/transthoracic & 57 & 23.2 & 130 & 1 & 5.26 & 3.51 & 1.75 & 0 \\
\hline 60505 & $\begin{array}{l}\text { Parathyroidectomy/exploration of parathyroids with } \\
\text { transthoracic echocardiogram }\end{array}$ & 32 & 23.06 & 94 & 1 & 0 & 0 & 0 & 0 \\
\hline 42426 & $\begin{array}{l}\text { Excision of parotid tumor/total parotid gland with } \\
\text { unilateral radical neck dissection }\end{array}$ & 100 & 22.66 & 184 & 2 & 6 & 3 & 3 & 0 \\
\hline 60252 & Total thyroidectomy/subtotal limited neck dissection & 1,235 & 22.01 & 131 & 1 & 2.83 & 2.75 & 1.46 & 0.24 \\
\hline 38720 & Cervical lymphadenectomy & 75 & 21.95 & 138 & 1 & 8 & 9.33 & 5.33 & 2.67 \\
\hline 60502 & $\begin{array}{l}\text { Parathyroidectomy/exploration of parathyroids, } \\
\text { re-exploration }\end{array}$ & 63 & 21.15 & 94 & 0 & 3.17 & 3.17 & 3.17 & 0 \\
\hline 42420 & $\begin{array}{l}\text { Excision of parotid tumor/total parotid gland dissection } \\
\text { and facial nerve preservation }\end{array}$ & 816 & 19.53 & 143 & 1 & 3.19 & 1.35 & 0.98 & 0.12 \\
\hline 60260 & Removal of remaining thyroidectomy tissue & 895 & 18.26 & 80 & 1 & 1.9 & 2.01 & 0.78 & 0 \\
\hline 60271 & Thyroidectomy substernal, cervical approach & 603 & 17.62 & 124 & 1 & 1.33 & 2.16 & 1.66 & 0.33 \\
\hline 42415 & $\begin{array}{l}\text { Excision of parotid tumor/lateral parotid gland dissection } \\
\text { and facial nerve preservation }\end{array}$ & 2,379 & 17.16 & 127 & 1 & 2.52 & 1.35 & 0.97 & 0.04 \\
\hline 60212 & $\begin{array}{l}\text { Partial unilateral thyroid lobectomy with contralateral } \\
\text { lobectomy }\end{array}$ & 83 & 16.43 & 98 & 1 & 2.41 & 1.2 & 0 & 0 \\
\hline 41130 & Glossectomy: hemiglossectomy & 71 & 15.74 & 71 & 1 & 12.68 & 4.23 & 8.45 & 1.41 \\
\hline 60500 & Parathyroidectomy/exploration of parathyroids & 2,741 & 15.6 & 85 & 0 & 1.42 & 2.12 & 0.62 & 0.07 \\
\hline 60240 & Total thyroidectomy & 6,699 & 15.04 & 121 & 1 & 1.81 & 2.27 & 1.13 & 0.15 \\
\hline
\end{tabular}

60500 Parathyroidectomy/exploration of parathyroids

15.04 
Table 1. Continued

\begin{tabular}{|c|c|c|c|c|c|c|c|c|c|}
\hline $\begin{array}{l}\text { CPT } \\
\text { Code }\end{array}$ & Procedure & Frequency & $\begin{array}{l}\text { Mean Work } \\
\text { RVU }\end{array}$ & $\begin{array}{c}\text { Median } \\
\text { Operative } \\
\text { Time, min }\end{array}$ & $\begin{array}{l}\text { Median } \\
\text { LOS, days }\end{array}$ & $\begin{array}{c}\text { Mean } \\
\text { Morbidity, } \\
\%\end{array}$ & $\begin{array}{c}\text { Mean Read- } \\
\text { mission, } \\
\%\end{array}$ & $\begin{array}{c}\text { Mean Reop- } \\
\text { eration, } \\
\%\end{array}$ & $\begin{array}{c}\text { Mean } \\
\text { Mortality } \\
\%\end{array}$ \\
\hline 60225 & $\begin{array}{l}\text { Total unilateral thyroid lobectomy with contralateral } \\
\text { lobectomy }\end{array}$ & 317 & 14.79 & 91 & 1 & 0.32 & 1.58 & 0.32 & 0 \\
\hline 42425 & Excision of parotid tumor/total gland en bloc removal & 44 & 13.42 & 131 & 1 & 4.55 & 2.27 & 6.82 & 0 \\
\hline 38700 & Suprahyoid lymphadenectomy & 55 & 12.81 & 104 & 1 & 0 & 0 & 0 & 0 \\
\hline 21044 & Excision of malignant tumor, mandible & 29 & 12.8 & 363 & 7 & 31.03 & 3.45 & 3.45 & 0 \\
\hline 42842 & Radical resection of tonsil without closure & 69 & 12.23 & 124 & 2 & 1.45 & 7.25 & 4.35 & 0 \\
\hline 42120 & Resection of palate/extensive resection of lesion & 66 & 11.86 & 57.5 & 0 & 4.55 & 1.52 & 0 & 1.52 \\
\hline 60210 & $\begin{array}{l}\text { Partial unilateral thyroid lobectomy with or without } \\
\text { isthmusectomy }\end{array}$ & 1,395 & 11.23 & 88 & 1 & 2.22 & 1.36 & 1.29 & 0.07 \\
\hline 60220 & $\begin{array}{l}\text { Total unilateral thyroid lobectomy with or without } \\
\text { isthmusectomy }\end{array}$ & 6,473 & 11.19 & 84 & 1 & 1.14 & 1.07 & 0.82 & 0.03 \\
\hline 41120 & Glossectomy: $<1 / 2$ tongue & 447 & 11.14 & 49 & 0 & 2.68 & 1.57 & 2.46 & 0 \\
\hline 21025 & Excision of bone, mandible & 83 & 10.03 & 355 & 6 & 26.51 & 3.61 & 7.23 & 1.2 \\
\hline 60200 & Excision of cyst/thyroid adenoma/isthmus transection & 134 & 10.02 & 65 & 0 & 2.24 & 2.99 & 0.75 & 0.75 \\
\hline 42410 & $\begin{array}{l}\text { Excision of parotid tumor/lateral lobe of parotid gland } \\
\text { without nerve dissection }\end{array}$ & 623 & 9.57 & 95 & 0 & 2.73 & 0.64 & 0.8 & 0 \\
\hline 42950 & Pharyngoplasty & 38 & 8.27 & 39.5 & 0 & 0 & 2.63 & 0 & 0 \\
\hline 38542 & Deep jugular node dissection & 58 & 7.95 & 54 & 0 & 0 & 3.45 & 1.72 & 0 \\
\hline 42440 & Excision of submandibular, submaxillary glands & 961 & 6.14 & 74 & 0 & 3.02 & 1.46 & 0.73 & 0.1 \\
\hline 42870 & Excision/destruction of lingual tonsil & 63 & 5.52 & 49 & 1 & 4.76 & 3.17 & 3.17 & 0 \\
\hline 42826 & Tonsillectomy: $1 / 2$, age $>12$ & 12,410 & 3.45 & 20 & 0 & 1.24 & 2.57 & 3.74 & 0.02 \\
\hline 41112 & $\begin{array}{l}\text { Excision of tongue lesion with closure of anterior } \\
\text { two-thirds }\end{array}$ & 319 & 2.83 & 21 & 0 & 0.31 & 1.88 & 0.31 & 0 \\
\hline 41116 & Excision of floor of mouth lesion & 108 & 2.52 & 38 & 0 & 2.78 & 4.63 & 0.93 & 0 \\
\hline 42808 & Excision/destruction of pharyngeal lesion & 118 & 2.35 & 15.5 & 0 & 2.54 & 2.54 & 0.85 & 0 \\
\hline 41110 & Excision of tongue lesion without closure & 141 & 1.56 & 27 & 0 & 0.71 & 0.71 & 0.71 & 0 \\
\hline N/A & All procedures evaluated & 41,554 & $16.32 \pm 9.49$ & $\begin{array}{r}133.55 \pm \\
111.29\end{array}$ & $1.67 \pm 2.43$ & $6.58 \pm 9.34$ & $3.62 \pm 3.46$ & $3.52 \pm 5.35$ & $0.26 \pm 0.56$ \\
\hline
\end{tabular}

CPT, Current Procedural Terminology. 

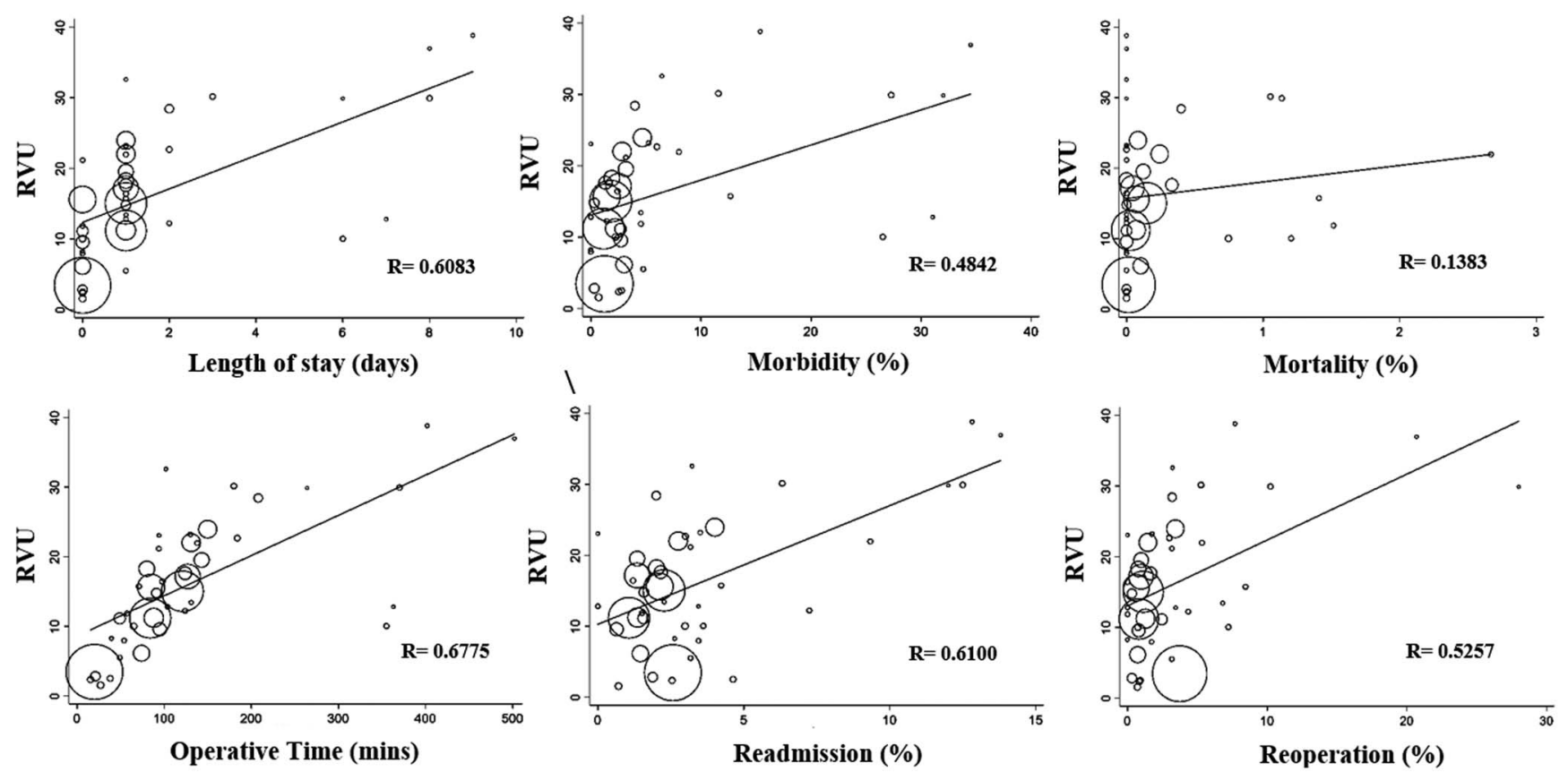

Figure. Correlation between the 6 surrogate objective measures of time and intensity of 43 surgical procedures and work relative value unit (RVU).

$(P=0.085)$. Readmission $(P=0.244)$ and LOS $(P=0.367)$ were not strongly associated with work RVUs using multivariable linear regression analysis. Using a significance threshold of $<0.1$, multivariable linear regression analysis was repeated with only morbidity, operative time, and reoperation. All 3 variables were statistically significant in this model: morbidity $(-0.9634,95 \% \mathrm{Cl}-1.5076$ to $-0.4193 ; P<0.001)$, operative time $(0.0973,95 \% \mathrm{Cl} 0.0619$ to $0.1327 ; P<0.001)$, and reoperation $(0.9701,95 \% \mathrm{Cl} 0.3434$ to $1.5968 ; P=0.003)$. The $R^{2}$ of this model was 0.6018 .

Table 2 shows the outliers of the bivariable linear regression and the multivariable linear regression models and the difference between the predicted and actual work RVUs. Excision of bone, mandible (CPT code 21025), work RVU of 10.03 units, was an outlier in multiple models, including the bivariable linear regression of operative time, LOS, and morbidity. Multivariable linear regression analysis of reoperation, morbidity, and operative time also found excision of bone, mandible to be an outlier, with a projected work RVU of 22.26 units, 12.23 units higher than the current work RVU.

Similarly, resection/excision of lesion infratemporal fossa space apex extradural (CPT code 61605), work RVU of 32.57 units, was an outlier in operative time, readmission, LOS, reoperation, and morbidity, as well as an outlier in the multivariable regression analysis of reoperation, morbidity, and operative time (19.48 units lower than the current work RVU).

Studentized residuals for the 43 different CPT codes based on univariable and multivariable linear regression analysis are shown in Table 3.

\section{DISCUSSION}

Of the 3 major considerations that account for the calculation of RVUs (physician work, the cost of running a practice, and opportunity cost of physician training), sur- geon work contributes $50.9 \%$ of the total calculation. To further understand surgeon work, it is important to note that the following variables are all included in calculating surgeon reimbursement: time to complete a service, technical skill and physical labor, cerebral effort and decisionmaking, and risk to the patient. ${ }^{4}$ Work RVUs are intended to encompass the following distinct components: preoperative assessment, operative time and effort, and inpatient postoperative management. ${ }^{8}$ As explained earlier, the RUC currently obtains work RVU estimates from physician surveys conducted by each respective specialty society. However, we believe that surrogate measures for time and intensity of procedures can be used so that work RVU assignments can be verified. Studies in different surgical specialties found that LOS, morbidity, mortality, reoperation, unplanned readmissions, and operative time are correlated with work RVUs and should be used in work RVU reevaluation. ${ }^{5,7}$ In 2007, Smith et al explained the effort of the Society of Thoracic Surgeons to use objective data such as operative time and LOS from the society database, conduct national surveys to estimate work intensity, and work with the RUC and CMS to achieve more equitable work RVU assignments for their cases. ${ }^{9}$ In fact, the mean work RVU in otolaryngology was found to be 3.05 units lower compared to general surgery, while that of cardiothoracic surgery was 7.78 units higher than general surgery in a 2019 study. ${ }^{5}$ Therefore, the field of otolaryngology could likely benefit from investigating these objective measures. The RUC should be informed of any discovered undervaluation compared to our surgical counterparts and subsequently lobbied for more accurate reimbursement for surgeon work in otolaryngology.

In a study that determined the correlation of work RVU with operative time, LOS, readmission, and reoperation of surgical procedures in various specialties, these 4 measures 
Table 2. Outlier Procedures Based on Univariable and Multivariable Linear Regressions With Projected Work Relative Value Unit (RVU)

\begin{tabular}{|c|c|c|c|c|c|c|}
\hline Variable & CPT Code & Procedure & $\begin{array}{l}\text { Studentized } \\
\text { Residuals }\end{array}$ & $\begin{array}{c}\text { Actual } \\
\text { Work RVU }\end{array}$ & $\begin{array}{l}\text { Projected } \\
\text { RVU }\end{array}$ & Difference \\
\hline \multirow[t]{3}{*}{ Operative time } & 21025 & Excision of bone, mandible & -3.1790 & 10.03 & 29.11 & 19.08 \\
\hline & 21044 & Excision of malignant tumor, mandible & -2.7302 & 12.8 & 29.57 & 16.77 \\
\hline & 61605 & Resection/excision of lesion infratemporal fossa space apex extradural & +2.7997 & 32.57 & 14.50 & -18.07 \\
\hline \multirow[t]{3}{*}{ Readmission } & 41116 & Excision of floor of mouth lesion & -2.1523 & 2.52 & 18.02 & 15.5 \\
\hline & 60254 & Total/subtotal thyroidectomy with radical neck dissection & +2.0495 & 28.42 & 13.62 & -14.8 \\
\hline & 61605 & Resection/excision of lesion infratemporal fossa space apex extradural & +2.3715 & 32.57 & 15.67 & -16.9 \\
\hline \multirow[t]{3}{*}{ Length of stay } & 21025 & Excision of bone, mandible & -2.4148 & 10.03 & 26.56 & 16.53 \\
\hline & 21044 & Excision of malignant tumor, mandible & -2.4073 & 12.8 & 28.93 & 16.13 \\
\hline & 61605 & Resection/excision of lesion infratemporal fossa space apex extradural & +2.5220 & 32.57 & 14.72 & -17.85 \\
\hline \multirow[t]{2}{*}{ Reoperation } & 31365 & Laryngectomy total with radical neck dissection & +2.4609 & 38.81 & 20.20 & -18.61 \\
\hline & 61605 & Resection/excision of lesion infratemporal fossa space apex extradural & +2.1344 & 32.57 & 16.04 & -16.53 \\
\hline \multirow[t]{4}{*}{ Morbidity } & 21025 & Excision of bone, mandible & -2.1423 & 10.03 & 26.11 & 16.08 \\
\hline & 21044 & Excision of malignant tumor, mandible & -2.1382 & 12.8 & 28.34 & 15.54 \\
\hline & 31365 & Laryngectomy total with radical neck dissection & +2.3279 & 38.81 & 20.64 & -18.17 \\
\hline & 61605 & Resection/excision of lesion infratemporal fossa space apex extradural & +2.0395 & 32.57 & 16.25 & -16.32 \\
\hline \multirow{3}{*}{$\begin{array}{l}\text { Reoperation, morbidity, } \\
\text { operative time }\end{array}$} & 21025 & Excision of bone, mandible & -2.3344 & 10.03 & 22.26 & 12.23 \\
\hline & 41135 & Partial glossectomy with unilateral radical neck dissection & +2.1208 & 30.14 & 17.71 & -12.43 \\
\hline & 61605 & Resection/excision of lesion infratemporal fossa space apex extradural & +3.6558 & 32.57 & 13.09 & -19.48 \\
\hline
\end{tabular}

Notes: Morbidity is defined as any serious adverse events that occurred within 30 days of the procedure. Reoperation is defined as return to the operating room within 30 days of the procedure. Operative time is defined as time from skin incision to skin closure of the procedure in minutes. Mortality is not included as no linear correlation was found between mortality and work relative value units $(95 \% \mathrm{Cl}$ -2.9493 to $7.6331 ; P=0.377$ )

CPT, Current Procedural Terminology. 


\begin{tabular}{|c|c|c|c|c|c|c|c|}
\hline $\begin{array}{l}\text { CPT } \\
\text { Code }\end{array}$ & Procedure & $\begin{array}{c}\text { Reoperation, } \\
\text { Morbidity, } \\
\text { Operative } \\
\text { Time }\end{array}$ & $\begin{array}{c}\text { Operative } \\
\text { Time }\end{array}$ & LOS & Morbidity & Readmission & Reoperation \\
\hline 31365 & Laryngectomy total with radical neck dissection & 0.1507 & 1.0828 & 0.7698 & 2.3279 & 1.0373 & 2.4609 \\
\hline 15756 & Free muscle/myocutaneous flap with microvascular anastomosis & -0.9991 & -0.1089 & 0.8162 & 0.9385 & 0.5329 & 0.6567 \\
\hline 61605 & $\begin{array}{l}\text { Resection or excision of neoplastic, vascular, or infectious lesion } \\
\text { of infratemporal fossa, petrous apex; extradural }\end{array}$ & 3.6558 & 2.7997 & 2.5220 & 2.0395 & 2.3715 & 2.1345 \\
\hline 41135 & Partial glossectomy with unilateral radical neck dissection & 2.1208 & 1.6312 & 1.4419 & 1.3891 & 1.2551 & 1.5381 \\
\hline 31360 & Total laryngectomy without neck dissection & 0.6995 & -0.0097 & -0.1989 & 0.4345 & -0.1829 & 0.92581 \\
\hline 41150 & Composite glossectomy with floor and mandibular resection & 0.4333 & 0.8729 & 0.4514 & 0.1373 & -0.0693 & -1.6773 \\
\hline 60254 & Total/subtotal thyroidectomy with radical neck dissection & 0.4528 & 1.1276 & 1.5289 & 1.6453 & 2.0495 & 1.5632 \\
\hline 38724 & Cervical lymphadenectomy with modified neck dissection & 0.6989 & 0.9565 & 1.2341 & 1.0334 & 0.9255 & 0.9556 \\
\hline 60270 & Thyroidectomy with substernal split/transthoracic & 1.2611 & 1.0157 & 1.1304 & 0.9053 & 0.9374 & 1.0596 \\
\hline 60505 & $\begin{array}{l}\text { Parathyroidectomy/exploration of parathyroids with } \\
\text { transthoracic echocardiogram }\end{array}$ & 1.2699 & 1.3062 & 1.1112 & 1.2163 & 1.7682 & 1.2573 \\
\hline 42426 & $\begin{array}{l}\text { Excision of parotid tumor/total parotid gland with unilateral } \\
\text { radical neck dissection }\end{array}$ & 0.2240 & 0.4877 & 0.7356 & 0.7942 & 0.9801 & 0.8430 \\
\hline 60252 & Total thyroidectomy/subtotal limited neck dissection & 0.7056 & 0.8334 & 0.9678 & 0.9074 & 0.9482 & 0.9440 \\
\hline 38720 & Cervical lymphadenectomy & 0.7803 & 0.7661 & 0.9596 & 0.5899 & -0.5371 & 0.4846 \\
\hline 60502 & Parathyroidectomy/exploration of parathyroids, re-exploration & 0.9355 & 1.0216 & 1.1802 & 0.7814 & 0.7365 & 0.6341 \\
\hline 42420 & $\begin{array}{l}\text { Excision of parotid tumor/total parotid gland dissection and } \\
\text { facial nerve preservation }\end{array}$ & 0.2418 & 0.3779 & 0.6343 & 0.5843 & 0.9350 & 0.6888 \\
\hline 60260 & Removal of remaining thyroidectomy tissue & 0.8632 & 0.7190 & 0.4657 & 0.5082 & 0.6120 & 0.5540 \\
\hline 60271 & Thyroidectomy substernal, cervical approach & -0.1673 & 0.2625 & 0.3811 & 0.4655 & 0.4942 & 0.3731 \\
\hline 42415 & $\begin{array}{l}\text { Excision of parotid tumor/lateral parotid gland dissection and } \\
\text { facial nerve preservation }\end{array}$ & 0.0072 & 0.1776 & 0.3205 & 0.3390 & 0.6156 & 0.3963 \\
\hline 60212 & $\begin{array}{l}\text { Partial unilateral thyroid lobectomy with contralateral } \\
\text { lobectomy }\end{array}$ & 0.4810 & 0.3070 & 0.2244 & 0.2583 & 0.5497 & 0.4185 \\
\hline 41130 & Glossectomy: hemiglossectomy & 1.1618 & 0.4320 & 0.1337 & -0.4283 & -0.2103 & -0.6427 \\
\hline 60500 & Parathyroidectomy/exploration of parathyroids & 0.2989 & 0.2961 & 0.4291 & 0.2174 & 0.2358 & 0.24418 \\
\hline 60240 & Total thyroidectomy & -0.3809 & -0.0783 & 0.0418 & 0.1279 & 0.1282 & 0.1163 \\
\hline 60225 & Total unilateral thyroid lobectomy with contralateral lobectomy & -0.0512 & 0.1317 & 0.0090 & 0.1860 & 0.2484 & 0.17964 \\
\hline 42425 & Excision of parotid tumor/total gland en bloc removal & -1.3202 & -0.3900 & -0.1709 & -0.2258 & -0.0858 & -0.7389 \\
\hline 38700 & Suprahyoid lymphadenectomy & -0.5817 & -0.2554 & -0.2510 & -0.0324 & 0.3387 & -0.0277 \\
\hline
\end{tabular}


Table 3. Continued

\begin{tabular}{|c|c|c|c|c|c|c|c|}
\hline $\begin{array}{l}\text { CPT } \\
\text { Code }\end{array}$ & Procedure & $\begin{array}{c}\text { Reoperation, } \\
\text { Morbidity, } \\
\text { Operative } \\
\text { Time }\end{array}$ & $\begin{array}{l}\text { Operative } \\
\text { Time }\end{array}$ & LOS & Morbidity & Readmission & Reoperation \\
\hline 21044 & Excision of malignant tumor, mandible & -0.5154 & -2.7302 & -2.4073 & -2.1382 & -0.4264 & -0.4229 \\
\hline 42842 & Radical resection of tonsil without closure & -1.5175 & -0.5021 & -0.6406 & -0.1867 & -1.3855 & -0.5971 \\
\hline 42120 & Resection of palate/extensive resection of lesion & 0.7299 & -0.0094 & -0.0651 & -0.4122 & -0.1247 & -0.1445 \\
\hline 60210 & $\begin{array}{l}\text { Partial unilateral thyroid lobectomy with or without } \\
\text { isthmusectomy }\end{array}$ & -0.4351 & -0.3490 & -0.4595 & -0.3516 & -0.1741 & -0.3694 \\
\hline 60220 & $\begin{array}{l}\text { Total unilateral thyroid lobectomy with or without } \\
\text { isthmusectomy }\end{array}$ & -0.4738 & -0.3220 & -0.4648 & -0.2933 & -0.1141 & -0.3205 \\
\hline 41120 & Glossectomy: $<1 / 2$ tongue & 0.0525 & -0.0421 & -0.1601 & -0.3894 & -0.2310 & -0.5144 \\
\hline 21025 & Excision of bone, mandible & -2.3344 & -3.1790 & -2.4148 & -2.1424 & -0.8330 & -1.2213 \\
\hline 60200 & Excision of cyst/thyroid adenoma/isthmus transection & -0.1813 & -0.3330 & -0.3081 & -0.4979 & -0.6932 & -0.4567 \\
\hline 42410 & $\begin{array}{l}\text { Excision of parotid tumor/lateral lobe of parotid gland without } \\
\text { nerve dissection }\end{array}$ & -0.6606 & -0.6442 & -0.3678 & -0.5808 & -0.2352 & -0.5188 \\
\hline 42950 & Pharyngoplasty & -0.2959 & -0.3742 & -0.5406 & -0.5781 & -0.8494 & -0.5886 \\
\hline 38542 & Deep jugular node dissection & -0.8552 & -0.5394 & -0.5833 & -0.6170 & -1.0779 & -0.8269 \\
\hline 42440 & Excision of submandibular, submaxillary glands & -0.8339 & -0.9682 & -0.8265 & -1.0168 & -0.8749 & -0.9400 \\
\hline 42870 & Excision/destruction of lingual tonsil & -0.6564 & -0.8506 & -1.2303 & -1.1995 & -1.3516 & -1.3087 \\
\hline 42826 & Tonsillectomy: $1 / 2$, age $>12$ & -1.2038 & -0.9139 & -1.1951 & -1.2466 & -1.5030 & -1.6529 \\
\hline 41112 & Excision of tongue lesion with closure of anterior two-thirds & -0.9014 & -1.0143 & -1.2816 & -1.2694 & -1.4300 & -1.3177 \\
\hline 41116 & Excision of floor of mouth lesion & -0.9341 & -1.2036 & -1.3251 & -1.4590 & -2.1523 & -1.4314 \\
\hline 42808 & Excision/destruction of pharyngeal lesion & -0.6285 & -1.0398 & -1.3491 & -1.4663 & -1.6547 & -1.4445 \\
\hline 41110 & Excision of tongue lesion without closure & -1.2159 & -1.2555 & -1.4611 & -1.4559 & -1.3403 & -1.5330 \\
\hline
\end{tabular}

LOS, length of stay. 
explained $80 \%$ of the variation in work RVUs. ${ }^{5}$ Multivariable linear regression analysis in our study revealed that only morbidity, operative time, and reoperation are statistically significant variables in the determination of work RVU and explained only $60.18 \%$ of work RVU calculation (the $R^{2}$ of the multivariable linear regression was 0.6018 ). The lack of statistical significance among other studied variables implies that work RVUs in otolaryngology, specifically head and neck surgery, are poorly correlated with studied objective measures. Our group believes that increased utilization of objective measures from available databases could improve the accuracy of work RVU assignment during updating processes.

Morbidity, an indicator for postoperative management work and risk to patients, was a negative predictor of work RVU by multivariable regression. All 43 CPT codes explored in our study were head and neck surgeries, and patients undergoing head and neck procedures typically have multiple medical comorbidities. ${ }^{10}$ This negative correlation leading to an undervaluation of work RVUs could be attributable to the lack of accounting for medical complexity and complications related to comorbidities that surgeons manage postoperatively. Similarly, LOS and readmission were not predictive of work RVUs by multivariable regression. The lack of association of work RVUs to LOS and readmission is concerning, as head and neck cancer cases are often linked to prolonged postoperative courses with high complication rates. In the literature, the average LOS and the readmission rate in head and neck cancer diagnoses were reported to be 6.6 days and $13.8 \%$, respectively. ${ }^{11,12}$ Therefore, morbidity, LOS, and readmission rate should be thoroughly incorporated in assigning work RVUs to avoid undercompensation for head and neck cancer surgeons.

Mortality was very weakly correlated to work RVUs. Multiple studies have corroborated the effect of mortality on work RVUs across surgical specialties. ${ }^{5,7,13-15}$ Because mortality rates associated with the procedures included in this study were so low, precisely assessing the association between work RVUs and mortality may not be possible. However, like our study, various studies also describe the poor relationship between mortality and case complexity with work RVUs. ${ }^{5,7,13-16}$ The reasons for this poor correlation are most likely multifactorial and confounded by patientrelated comorbidities and the health care resources, or lack thereof, available to them upon discharge. ${ }^{7,16}$

In addition, our study identified various outlying procedures. For example, excision of bone mandible (CPT code 21025) was found to be undervalued in multiple analyses, meaning surgeons were not properly compensated for completing the procedure. This difference could result from the procedure being improperly evaluated, leading to an erroneous work RVU assignment. However, the actual operative time was long (355 minutes). This finding raises the possibility that the correct CPT code is not being selected when billing for this procedure. The literature documents that CPT coding errors are prevalent across various medical specialties. ${ }^{17,18}$ Conceivably, with regard to excision of bone mandible (CPT code 21025), the following similar but more complex CPT codes were not selected: 21040 (excision of benign tumor or cyst of mandible by enucleation and/or curettage) with a work RVU of 15.11; 21046 (excision of benign tumor or cyst of mandible requiring intra-oral osteotomy [eg, locally aggressive or destructive lesion]), with a work RVU of 32.44; or 21045 (excision of malignant tumor of mandible, radical resection), with a work RVU of 35.41 . This point affirms the need for surgeons to take ownership of accurate codes and selection of codes to avoid an undervaluation of procedures. The projected work RVU for excision of bone, mandible resulting from our study's multivariable analysis is 22.26 units, 12.23 units higher than the actual work RVU; therefore, physicians and surgeons must be careful to select the code that best fits their procedure for proper compensation. A similar finding of undervalued work RVU was seen in CPT code 21044 (excision of malignant tumor, mandible), which has a median operative time of 363 minutes and a work RVU of 12.8 units. CPT code descriptions could also be updated to make them clearer for intended use. The long operative times of these 2 procedures call into question whether the procedures included reconstruction. We avoided this type of error by selecting cases for which only a single CPT code was billed.

An example of an overcompensated procedure is resection/excision of lesion infratemporal fossa space apex extradural (CPT code 61605). This procedure had a lower operative time and fewer complications than predicted. Given a deeper look, perhaps this procedure is compensated for the anatomically difficult locations surrounded by major structures that induce a potential for elevated complications. These complications may be minimized by the expertise and extensive training completed by the surgeons who perform these operations. Therefore, considering the possible risk to patients weighing on the surgeon and the opportunity cost payoff for training time, this procedure may be properly reimbursed. A future direction of this study could be to analyze the cost-effectiveness associated with the time, money, and effort surgeons spend in subspecialty training, as well as meeting continued medical education requirements to successfully perform high-risk procedures.

Although we believe that the results of our study are compelling and should be taken into consideration when assigning work RVUs to the studied procedures, we also acknowledge the limitations of our data. First, the NSQIP database only includes data from major cases from a sampling of institutions around the country. Together with our strict exclusion of cases with concurrent CPT codes and more than one surgeon, only 43 procedures were included, and all were head and neck procedures. Although the strict exclusion criteria made our results more readily ascribable to procedures involving a single CPT code, these criteria may limit the application of our findings to concurrent or multidisciplinary surgeries. Further studies may be warranted to explore how these objective measures could be used to reimburse for cases associated with multiple surgeons or CPT codes. For example, many head and neck surgeries require reconstruction; these procedures are likely to be more time consuming and to require multiple surgeons compared to surgeries that involve a single discipline and do not require reconstruction. Analysis of individual surgeon work associated with these complex and multidisciplinary procedures, therefore, is a potential outlet for future exploration. Our study only investigated 6 objective measures that could contribute to the time and intensity of the preservice, intraservice, and postservice building blocks of work RVUs. These variables do not represent the only factors that contribute to surgeon time 
and case complexity. Therefore, the data need to be interpreted with caution. Finally, because the NSQIP database represents a sampling of cases from a group of 703 large NSQIP hospitals, the data may not be generalizable among all institutions. ${ }^{19}$

\section{CONCLUSION}

This study exposes incongruities between the variables studied in the NSQIP database and assigned work RVUs for head and neck procedures. Objective surrogate measures for surgeon work could improve work RVU assignment accuracy for the outlier procedures that are not accurately represented. Using such objective measures may be more reliable compared to the current system of work RVU assignment based on physician survey. Future investigation with additional objective parameters may be further beneficial to make work RVU assignment less subjective. Outlying work RVUs, therefore, should be reevaluated by the RUC for proper compensation based on objective measures of surgeon work.

\section{ACKNOWLEDGMENTS}

The authors have no financial or proprietary interest in the subject matter of this article.

\section{REFERENCES}

1. Laugesen MJ. The resource-based relative value scale and physician reimbursement policy. Chest. 2014;146(5):1413-1419. doi: 10.1378/chest.13-2367

2. Solomon A, Martino S. Relative value units: practical productivity measurement. Radiol Manage. 1991;13(1):33-37.

3. Conoley PM, Vernon SW. Productivity of radiologists: estimates based on analysis of relative value units. AJR Am J Roentgenol. 1991;157(6):1337-1340. doi: 10.2214/ajr.157.6.1950885

4. Jacobs JP, Lahey SJ, Nichols FC, et al.; Society of Thoracic Surgeons Workforce on Coding and Reimbursement. How is physician work valued? Ann Thorac Surg. 2017;103(2):373-380. doi: 10.1016/j.athoracsur.2016.11.059

5. Childers CP, Dworsky JQ, Russell MM, Maggard-Gibbons M. Association of work measures and specialty with assigned work relative value units among surgeons. JAMA Surg. 2019;154(10):915-921. doi: 10.1001/jamasurg.2019.2295

6. Shah DR, Bold RJ, Yang AD, Khatri VP, Martinez SR, Canter RJ. Relative value units poorly correlate with measures of surgical effort and complexity. J Surg Res. 2014;190(2):465-470. doi: 10.1016/j.jss.2014.05.052

7. Gan ZS, Wood CM, Hayon S, et al. Correlation of relative value units with surgical complexity and physician workload in urology. Urology. 2020;139:71-77. doi: 10.1016/j.urology.2019.12.044

8. Hayon S, Deal A, Tan HJ, et al. Is the relative value of surgeon effort equal across surgical specialties? Surgery. 2020;168(3):365-370. doi: 10.1016/j.surg.2020.04.018

9. Smith PK, Mayer JE Jr, Kanter KR, et al.; STS/AATS Workforce on Nomenclature and Coding. Physician payment for 2007: a description of the process by which major changes in valuation of cardiothoracic surgical procedures occurred. Ann Thorac Surg. 2007;83(1):12-20. doi: 10.1016/j.athoracsur.2006.11.058

10. Paleri V, Wight RG, Silver CE, et al. Comorbidity in head and neck cancer: a critical appraisal and recommendations for practice. Oral Oncol. 2010;46(10):712-719. doi: 10.1016/j.oraloncology.2010.07.008

11. Adjei Boakye E, Johnston KJ, Moulin TA, et al. Factors associated with head and neck cancer hospitalization cost and length of stay-a national study. Am J Clin Oncol. 2019;42(2):172-178. doi: 10.1097/COC.0000000000000487

12. Ghiam MK, Langerman A, Sargi Z, Rohde S. Head and neck cancer patients: rates, reasons, and risk factors for 30-day unplanned readmission. Otolaryngol Head Neck Surg. 2018;159(1):149-157. doi: 10.1177/0194599818776633

13. Sodhi N, Patel Y, Berger RJ, et al. Comparison of a posterior versus anterior approach for lumbar interbody fusion surgery based on relative value units. Surg Technol Int. 2019;35:363-368.

14. Little DC, St Peter SD, Calkins CM, et al. Relative value units correlate with pediatric surgeons' operating time: when perceived myth becomes reality. J Pediatr Surg. 2006;41(1):234-238; discussion 234-238. doi: 10.1016/j.jpedsurg.2005.10.044

15. Morris MS, Deierhoi RJ, Richman JS, Altom LK, Hawn MT. The relationship between timing of surgical complications and hospital readmission. JAMA Surg. 2014;149(4):348-354. doi: 10.1001/jamasurg.2013.4064

16. Schwartz DA, Hui $X$, Velopulos CG, et al. Does relative value unit-based compensation shortchange the acute care surgeon? J Trauma Acute Care Surg. 2014;76(1):84-92; discussion 92-94. doi: 10.1097/TA.0b013e3182ab1ae3

17. Balla $F$, Garwe $T$, Motghare $P$, et al. Evaluating coding accuracy in general surgery residents' accreditation council for graduate medical education procedural case logs. J Surg Educ. 2016;73(6):e59-e63. doi: 10.1016/j.jsurg.2016.07.017

18. Deeken-Draisey A, Ritchie A, Yang GY, et al. Current procedural terminology coding for surgical pathology: a review and one academic center's experience with pathologist-verified coding. Arch Pathol Lab Med. 2018;142(12):1524-1532. doi: 10.5858/arpa.2017-0190-RA

19. ACS National Surgical Quality Improvement Program. American College of Surgeons. 2020. Accessed July 12, 2020. www.facs.org/quality-programs/acs-nsqip

This article meets the Accreditation Council for Graduate Medical Education and the American Board of Medical Specialties Maintenance of Certification competencies for Patient Care, Medical Knowledge, Systems-Based Practice, and Practice-Based Learning and Improvement.

C2021 by the author(s); licensee Ochsner Journal, Ochsner Clinic Foundation, New Orleans, LA. This article is an open (C) (i) access article distributed under the terms and conditions of the Creative Commons Attribution (CC BY) license (creativecommons.org/licenses/by/4.0/legalcode) that permits unrestricted use, distribution, and reproduction in any medium, provided the original author(s) and source are credited. 